This item is the archived peer-reviewed author-version of:

Sleep and Alzheimer's disease : a pivotal role for the suprachiasmatic nucleus

\title{
Reference:
}

Van Erum Jan, Van Dam Debby, De Deyn Peter Paul.- Sleep and Alzheimer's disease : a pivotal role for the suprachiasmatic nucleus Sleep medicine review s - ISSN 1087-0792 - 40(2018), p. 17-27

Full text (Publisher's DOI): https://doi.org/10.1016/J.SMRV.2017.07.005 


\section{Sleep and Alzheimer's disease: A pivotal role for the suprachiasmatic nucleus?}

Jan Van Erum ${ }^{1}$, Debby Van Dam ${ }^{1,2}$, Peter Paul De Deyn ${ }^{1,2,3, *}$

${ }^{1}$ Laboratory of Neurochemistry and Behavior, Institute Born-Bunge, Department of Biomedical Sciences, University of Antwerp, Wilrijk (Antwerp), Belgium.

${ }^{2}$ Department of Neurology and Alzheimer Research Center, University of Groningen and University Medical Center Groningen (UMCG), Groningen, The Netherlands.

${ }^{3}$ Department of Neurology, Memory Clinic of Hospital Network Antwerp (ZNA) Middelheim and Hoge Beuken, Antwerp, Belgium

*Corresponding author.

(Peter Paul De Deyn)

Address: Campus Drie Eiken, Universiteitsplein 1, 2610 Wilrijk, Belgium

Email: peter.dedeyn@uantwerpen.be

Tel : +3232652620

Fax: +3232652669

Running Head

'ALZHEIMER'S DISEASE AND THE SUPRACHIASMATIC NUCLEUS'

\section{Acknowledgements}

This work was financed by the Interuniversity Poles of Attraction (IAP Network P7/16) of the Belgian Federal Science Policy Office, the Belgian Foundation for Alzheimer Research (SAO -FRA; grant \#15002), the agreement between Institute Born-Bunge and the University of Antwerp, the Medical Research Foundation Antwerp, the Thomas Riellaerts research fund, and Neurosearch Antwerp. The authors have no conflict of interest to declare. 


\section{Summary}

Alzheimer's disease (AD), which accounts for most of the dementia cases, is, aside from cognitive deterioration, often characterized by the presence of non-cognitive symptoms. Society is desperately in need for interventions that alleviate the economic and social burden related to AD. Circadian dysrhythmia, one of these symptoms in particular, immensely decreases the self-care ability of ADpatients and is one of the main reasons of caregiver exhaustion. Studies suggest that these circadian disturbances form the root of sleep-wake problems, diagnosed in more than half of AD patients. Sleep abnormalities have generally been considered merely a consequence of AD pathology. Recent evidence suggests that a bidirectional relationship exists between sleep and $A D$, and that poor sleep might negatively impact amyloid burden, as well as cognition. The suprachiasmatic nucleus (SCN), the main circadian pacemaker, is subjected to several alterations during the course of the disease. Its functional deterioration might fulfill a crucial role in the relation between AD pathophysiology and the development of sleep abnormalities. This review aims to give a concise overview of the anatomy and physiology of the SCN, address how AD pathology precisely impacts the $\mathrm{SCN}$ and to what degree these alterations can contribute to the progression of the disease.

\section{Keywords}

Circadian rhythm; suprachiasmatic nucleus; molecular clock; sleep; aging; Alzheimer's disease; dementia 


\section{Abbreviations}

\begin{tabular}{|ll|}
\hline Acetylcholine & ACh \\
Acetylcholinesterase inhibitor & AChEI \\
Alzheimer's disease & $\mathrm{AD}$ \\
Amyloid-beta & $\mathrm{AB}$ \\
Arginine vasopressin & $\mathrm{AVP}$ \\
Behavioral and psychological signs and symptoms of dementia & $\mathrm{BPSD}$ \\
Brain and muscle Arnt-like protein & $\mathrm{BMAL}$ \\
Circadian locomotor output cycles kaput & $\mathrm{CLOCK}$ \\
Cryptochrome & $\mathrm{CRY}$ \\
Dorsomedial nucleus of the hypothalamus & $\mathrm{DMN}$ \\
gamma-Aminobutyric acid & $\mathrm{GABA}$ \\
Interstitial fluid & $\mathrm{ISF}$ \\
Intracerebroventricular & $\mathrm{ICV}$ \\
IKB kinase & $\mathrm{IKK}$ \\
Melatonin receptor 1 & $\mathrm{MT} 1$ \\
Melatonin receptor 2 & $\mathrm{MT} 2$ \\
Neurofibrillary tangles & $\mathrm{NFTs}$ \\
Neuropsychiatric symptoms & $\mathrm{NPS}$ \\
Neurotensin & $\mathrm{NT}$ \\
Non-rapid eye movement & $\mathrm{NREM}$ \\
Nuclear factor kappa-light-chain-enhancer of activated B cells & $\mathrm{NF}-\mathrm{KB}$ \\
Paraventricular nucleus & $\mathrm{PVN}$ \\
Period & $\mathrm{PER}$ \\
Prokineticin-2 & $\mathrm{PK}-2$ \\
Rapid eye movement & $\mathrm{REM}$ \\
Retinoid-related orphan receptor & $\mathrm{ROR}$ \\
Reverse erythroblastosis virus & $\mathrm{REV}-\mathrm{ERB}$ \\
Slow-wave sleep & $\mathrm{SWS}$ \\
Subparaventricular zone & $\mathrm{SPZ}$ \\
Suprachiasmatic nucleus & $\mathrm{SCN}$ \\
Total sleep time & $\mathrm{TST}$ \\
Transforming growth factor- $\alpha$ & $\mathrm{TGF}-\alpha$ \\
Vasoactive intestinal peptide & $\mathrm{VIP}$ \\
Ventrolateral preoptic nucleus & $\mathrm{VLPO}$ \\
\hline
\end{tabular}




\section{Introduction}

Over the last century, improvements in health care have enabled mankind to live a healthier and longer life. However, as a consequence, the prevalence of non-communicable diseases, including dementia, has skyrocketed. Currently, around 47 million people worldwide are living with dementia. Moreover, this number is expected to double by 2030 , imposing an unattainable economic and social burden on society [1]. Of all dementias, Alzheimer's disease (AD) is the most prevalent, accounting for up to $75 \%$ of all dementia cases $[2] . A D$ is a neurodegenerative disorder, which is typically characterized by neuronal loss, gliosis, dystrophic neurites and the accumulation of proteinaceous aggregates [3]. Neurofibrillary tangles (NFTs), aggregates of hyperphosphorylated tau protein, are mostly observed in the intracellular milieu, where they compromise axonal transport and structural maintenance [4]. Deposits of insoluble amyloid-beta $(A \beta)$ in the extracellular space are assumed to be most crucial in the pathogenesis of AD. According to the amyloid hypothesis [5], these amyloid plaques drive the progressive neuronal damage that fully characterizes the disease. Moreover, fibrillar amyloid depositions in medium-sized and small cerebral vessels, better known as cerebral amyloid angiopathy, play an active role in the process of neurodegeneration through ischemic, hemorrhagic and apoptotic mechanisms [6].

As a result of these neurodegenerative processes, $A D$ patients present with prominent cognitive deficits. Initially, these cognitive symptoms are relatively minor, ranging from limited forgetfulness to short-term memory dysfunction. At later stages of the disease, however, long-term memory deficits become more prominent, and are eventually accompanied by executive dysfunction and helplessness [7]. Aside from cognitive deterioration, up to $80 \%$ of all $A D$ patients also display noncognitive symptoms in the course of the disease [8-10]. These symptoms comprise psychosis, as well as affective and behavioral changes and are commonly denominated as neuropsychiatric symptoms (NPS), formerly known as behavioral and psychological signs and symptoms of dementia (BPSD) [11]. NPS have been increasingly identified as a research priority, since they result in 
suffering, premature institutionalization, increased costs of care, and significant loss in quality of life for the patients, family and caregivers [12]. Seven main categories of NPS can be distinguished: paranoid and delusional ideation, hallucinations, affective disturbances, anxieties and phobias, aggressiveness, activity disturbances and diurnal rhythm disturbances [13]. The latter, circadian dysrhythmia, participates in the emergence of the sundowning syndrome, a phenomenon characterized by the exacerbation of neuropsychiatric symptoms in the late afternoon, evening or night. Around $45 \%$ of dementing subjects display agitation, restlessness and confusion at sunset. Also, 25 to $60 \%$ of all AD patients are diagnosed with sleep disorders and sleep abnormalities [14, 15], which often arise prior to the appearance of cognitive decline, and are among the first noticeable symptoms [16]. The sleep architecture of $A D$ patients is significantly different from aged control individuals, which manifests itself in a quantitative reduction of slow-wave sleep (SWS) and rapid eye movement (REM) sleep [17]. Furthermore, their sleep-wake cycle is often more fragmented and the overall daytime alertness is decreased [18-20], resulting in longer and more nocturnal awakenings and daytime naps [21, 22]. Sleep disorders and sundowning decrease the selfcare ability of $A D$ patients, are among the main reasons for caregiver exhaustion and greatly impact the rate of institutionalization $[23,24]$. Since the circadian system co-forms the foundation of the sleep-wake cycle and given the fact that also other circadian rhythms, including motor activity, body temperature and several hormone secretions are affected, sleep disturbances probably arise from alterations in the circadian rhythm $[19,25,26]$. Since relatively few studies have been conducted to substantiate this hypothesis [27-29], this review will try to highlight the importance of the circadian system in the context of AD by specifically focusing on the development of sleep-wake disturbances and giving a clear overview of the role of the suprachiasmatic nucleus (SCN), the primary circadian pacemaker in mammals, in this matter.

\section{Anatomy and physiology of the circadian pacemaker}


Mammalian behavior and physiology are entrained to the 24-hour environmental light/dark cycle. Such entrainment is achieved by an endogenous circadian clock, which enables the organism to anticipate to environmental changes and adapt to new conditions [30]. This circadian timing system is comprised of a central pacemaker along with afferent and efferent pathways. The SCN has been widely accepted as the central circadian pacemaker, as was demonstrated by the restoration of circadian rhythmicity in arrhythmic SCN-lesioned rats that were implanted with fetal SCN material [31-33], and in which the recovered rhythms had the characteristics of the donor, not the host [34]. The SCN is a small hypothalamic nucleus located dorsally of the optic chiasm. Each unilateral SCN has around 10,000 neurons and constitutes two main neuronal populations: an arginine vasopressin (AVP)-positive neuronal population occupying the dorsal shell region of the nucleus, and vasoactive intestinal peptide (VIP)-positive neurons located in the ventral core region [35]. AVP-expressing neurons secrete AVP in a circadian pattern. Studies in AVP-deficient Brattleboro rats have demonstrated that the presence of AVP may not be critical to maintain a coherent circadian rhythm $[36,37]$. However, the amplitude of certain circadian rhythms (e.g., sleep) is significantly affected in the absence of AVP [38], suggesting that the circadian release of AVP is responsible for the modulation of the amplitude of rhythms rather than its generation. VIP signaling on the other hand, is necessary for the generation and coordination of daily behavioral and physiological rhythms. Through activation of its VPAC $_{2}$ receptor, VIP is able to promote circadian rhythmicity in nonpacemaking SCN neurons, and maintain synchrony between intrinsically rhythmic neurons [39]. The exact roll of NT in the establishment of circadian rhythms is not completely understood at present. Evidence suggests that NT is able to increase the discharge rate of $\mathrm{SCN}$ neurons and phase shift their firing rhythm $[40,41]$. These findings, together with the fact that NT receptors are localized in the ventral region of the SCN [42-44], raise the possibility that this neuropeptide plays a role in the modulation of the central clock to environmental stimuli. 
The ventral core region receives direct information about light intensity, the strongest synchronizer of circadian rhythm (zeitgeber), via the retinohypothalamic tract, which originates from retinal melanopsin-containing ganglion cells $[45,46]$. The SCN also receives input from the thalamic intergeniculate leaflet and from the serotonergic raphe nuclei in the brainstem. Although light intensity is the strongest zeitgeber, these last two pathways allow non-photic entrainment by, for example, food intake, physical exercise and social cues [47]. The fact that totally blind people display a high incidence of free-running rhythms, even though they have ample access to nonphotic time cues, underline the importance of light exposure for normal entrainment for circadian rhythms [48].

The circadian clock in the SCN is based on a delayed negative transcriptional feedback loop (Figure 1). CLOCK/BMAL1 protein dimers bind to E-box cis-regulatory enhancer sequences and directly and indirectly promote the transcription of Period (Per1, Per2, Per3), Cryptochrome (Cry1 and Cry2), $\underline{\text { retinoid-related orphan receptor }}(\underline{\text { Ror })}$ and reverse erythroblastosis virus (Rev-Erb) genes. Consequently, PER, CRY, ROR and REV-ERB proteins accumulate in the cytosol [49]. PER is phosphorylated and when a critical level is reached, PER and CRY dimerize, after which the complex is translocated to the nucleus [50]. In the nucleus, CRY again suppresses CLOCK-BMAL1-induced

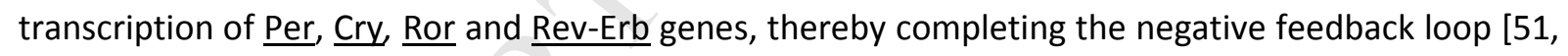
52]. ROR and REV-ERB also translocate to the nucleus where they regulate transcription of the Bmal1 gene by antagonistically competing for the RORE sequence [53]. This generates a rhythmic level of BMAL1 and hence CLOCK-BMAL1 protein levels. Nuclear levels of PER and CRY reach a maximum at the transition from day to night, while BMAL1 levels are highest at the transition from night to day. ROR and REV-ERB maxima occur somewhere in-between [54]. Although the mechanisms that coordinate the phase delay between these nuclear protein levels remain largely unknown, it is clear that the timing of nuclear entry is crucial in circadian organization. The transcriptional autoregulatory feedback loop is phylogenetically highly conserved, existing also in Drosophila $\underline{\text { melanogaster }}$ or fruitfly [55] and Caenorhabditis elegans [56], emphasizing its significance. At the 
same time however, the system is quite vulnerable to disruptions. Since the different clock components display distinct characteristics and diversely affect the clock's functioning, any alterations in gene expression or protein translation can severely impair the functioning of the entire mechanism. Knockout mouse models in which certain clock genes (e.g., Bmal1 and $\underline{\text { Cry }}$ ) have been permanently inactivated, phenotypically display disruptions of the sleep-wake cycle and other circadian rhythms [57-59], and hence provide proof of this concept. How the cell-autonomous circadian oscillators are integrated into a functional neuronal network is thoroughly reviewed by Welsh and colleagues [60].

Hence, the SCN is composed of thousands of oscillating neurons, each dependent on transcriptional translational feedback loops of a set of genes. Considering the former, it is surprising that all these individual SCN neurons can be integrated into a coherent pacemaker that can govern the circadian behavior of a whole organism, particularly the sleep-wake cycle. Precisely how the oscillating genes are linked to the output of the SCN is currently unknown. Yet, the different pathways that the SCN has at its disposal and uses to translate these molecular oscillating processes to non-rhythmic effector cells have been numerously described [61-65] (Figure 2). Most of the SCN projections are intra-hypothalamic and are in close communication with sleep-wake centers. Nevertheless, only few SCN efferents project to the ventrolateral preoptic nucleus (VLPO) or lateral hypothalamus monosynaptically [64-66]. There is even no monosynaptic output to the arousal sites in the brainstem. Instead, most SCN efferents are directed at the subparaventricular zone (SPZ) and the dorsomedial nucleus of the hypothalamus (DMN) and reach their target area via polysynaptic connections $[67,68]$. The SPZ, which extends dorsally and caudally from the SCN to the ventral edge of the hypothalamic paraventricular nucleus (PVN) [69], appears to be a specialized route through which circadian signals reach sleep-wake centers. At least, the ventral part (vSPZ) does, since only ventral lesions of the SPZ abolished rhythms of rest-activity, sleep-wake cycles and feeding, while dorsal lesions mainly affect the circadian rhythm of body temperature [70]. 
The SCN and vSPZ, in turn, both have dense projections the DMN [71, 72], which then again sends strong gamma-Aminobutyric acid-ergic (GABAergic) projections to the VLPO [72] and glutamatergic projections to the orexinergic lateral hypothalamic area [73]. The rationale behind such polysynaptic pathway is probably that it allows for the integration of light-entrained circadian cues from the SCN with non-photic environmental (e.g., feeding) cues to establish sleep-wake patterns that meet the organisms needs [66].

Other efferent pathways worth mentioning are the polysynaptic projections from the SCN to the PVN, which are important in the circadian control of the pineal hormone melatonin [74]. This pathway has revealed a remarkable feature of the SCN. The majority of SCN neurons are GABAergic [75], and even so most projections that reach the pineal gland are GABAergic [74]. However, a certain proportion of SCN neurons might be glutamatergic, and therefore excitatory in origin [76, 77]. Experiments with GABA and glutamate antagonists have indeed demonstrated that the SCN exerts a GABA-mediated inhibition of melatonin secretion during the subjective day, and a glutamatemediated secretion during the subjective night $[78,79]$. Such control, balanced by glutamatergic and GABAergic inputs have also been described for other biological rhythms (e.g., plasma glucose) [80], and therefore seem very plausible. Melatonin is a serotonin-derived hormone that provides important feedback to the SCN. Through activation of the melatonin receptors $1\left(\mathrm{MT}_{1}\right)$, melatonin can inhibit SCN neuronal activity, thereby promoting sleep. Additionally, activation of $\mathrm{MT}_{2}$ (and possibly also $\mathrm{MT}_{1}$ ) can cause phase shifting of the $\mathrm{SCN}$ firing rhythms [81].

Aside from these synaptic transmission pathways, there is now clear evidence that also certain diffusible factors are implicated in the regulation of the sleep-wake rhythm. This paracrine signaling became obvious after experiments in which transplants of the SCN restored circadian activity rhythms to animals whose own SCN had been ablated, even though the SCN grafts were encapsulated with a semipermeable polymeric membrane, thereby preventing the formation of axonal connections [82]. Up until now, two paracrine factors have been proposed to be responsible for this restoration of circadian function: transforming growth factor- $\alpha$ (TGF- $\alpha$ ) and prokineticin-2 
(PK-2). Intracerebroventricular (ICV) infusion of TGF- $\alpha$ suppresses wheel-running behavior in Syrian hamsters and, like SPZ lesions, disrupts the timing of the sleep-wake cycle, without altering the duration of the different vigilance states [83]. Similarly, ICV injection of PK-2 suppresses locomotor activity in rats [84]. Moreover, both factors are expressed by SCN cells and bind to receptors in the SPZ and DMN, both major target areas of the SCN $[83,84]$. Thus, it appears that both factors are implied in clock-dependent suppression of activity and perhaps could be critical initiators of the sleeping period. So far, no diffusible factors that promote arousal and activity have been found.

Another breakthrough in the understanding of the SCN clock was procured by neurophysiology studies in freely moving rodents. Inouye and colleagues performed in vivo multi-unit activity recordings and demonstrated that the SCN displays a diurnal pattern in electrical activity. SCN neurons of nocturnal rodents had a higher spontaneous activity rate during the light phase than the dark phase. Moreover, this pattern persisted when the animals were placed in constant environmental light conditions, suggesting that this diurnal activity pattern is intrinsic to the SCN neurons of the circadian clock, and is not influenced by external cues [85, 86]. A similar circadian pattern was described in a diurnal chipmunk, which suggests that the day/night preference of a species also reflects a differential effect of SCN output on downstream behavioral effectors $[87,88]$. Whether these results are representative for all diurnal animals remains questionable. However, clock gene expression (Period) in the Nile grass rat, a diurnal animal, has also been proven to phase similarly to clock genes of nocturnal animals [89]. During the aging process, SCN electrical activity has been reported to decrease in laboratory animals $[90,91]$. Could alterations in the electrical activity of the SCN also be the foundation of circadian dysrhythmia in AD?

\section{The SCN in Alzheimer's disease}

\subsection{Senescence-related alterations of the SCN}


Surprisingly, an adequate circadian rhythm has been associated with longevity. Transplantation of neonatal SCN tissue in old hamsters increased lifespan more than four months [92]. Moreover, the circadian rhythm of aged mice improved after receiving a SCN-containing transplant of fetal tissue in the third ventricle [93]. Intuitively, we assume that the reduced SCN function in senescent organisms can be explained by neurodegeneration. However, animal investigations of the neuronal and glial cell populations in the SCN reported quite ambiguous results. Madeira et al. analyzed the SCN of male and female adult and aged Wistar rats, and did not observe any age-related differences in the total number of neurons and astrocytes [94]. Similarly, although no effect of age on total size of the SCN could be demonstrated in F344/N rats, Tsakuhara and others reported a decrease in the number of SCN neurons in aged compared to young rats [95]. This age-related neuronal loss could, however, not be confirmed in rhesus monkeys [96]. The monkey hypothalamus did not display evidence of significant reductions in neuron or glia numbers, nor in the volume of other brain areas (including the $\mathrm{SCN}$ ), although a trend towards an age-related decline in $\mathrm{SCN}$ volume and neuron number in females could be observed. Hence, this study provides evidence that normal aging probably does not lead to a loss of neurons in monkey hypothalamus, and that alterations in homeostatic functioning associated with aging (e.g., circadian disturbances) likely reflect altered physiological functions rather than simple cell loss [96]. Reductions of synaptogenesis and biochemical alterations in the neuronal membrane have been described in the course of aging [97-99], and could reflect these underlying physiological disturbances. The neuronal membrane, a major site of action for processes like the conduction of neuronal information, control of ion channels and maintenance of various receptors, increases in rigidity with age [99]. Considerable evidence suggests that this decrease in membrane fluidity is due to disruptions in cholesterol homeostasis [97, 99-101]. Altered membrane fluidity can profoundly influence the action and density of receptor systems, for example VIP [102] and Nmethyl-D-aspartate [103], and therefore impact SCN function in numerous ways.

Clinically, neurodegenerative processes in the SCN have been demonstrated in the brains of senescent people, as well as a disturbed functional activity $[104,105]$. No cell loss in the SCN was 
apparent before the age of 80 years, yet, at a very old age (80-100 years old), when circadian disturbances are often present, a prominent decrease in the total cell number was observed. Similar to description above, these findings suggest that neurodegeneration might be a rather late phenomenon in the development of circadian dysrhythmia [28]. Alterations in membrane properties, neurotransmitter levels, or dendritic and synaptic contacts [106] might be earlier culprits of SCN dysfunction, and therefore need to be a primary directive in future investigations.

\section{2. $\underline{\mathrm{SCN} \text { alterations in } \mathrm{AD}}$}

Circadian disturbances are far more pronounced in AD than in normal aging [25]. Equally, the cell loss observed in the SCN of AD patients is more extensive [28]. In AD patients, the overall volume of the SCN and total SCN cell number have been reported to decrease [28]. Loss of AVP, VIP and neurotensin (NT)-expressing neurons [27, 107, 108], along with an increase of astrocytes, is indicative of a decreased functioning of the SCN [27]. Since all these neuropeptides play an important role in the maintenance of the circadian rhythm, loss of AVP, VIP or VPAC2 and NT may disrupt the normal entrainment and synchronization of circadian behavior. Hence, a decrease in neuropeptide levels due to neuronal loss might, at least partially, be responsible for diurnal behavioral disorders in AD.

In response to neuronal loss, reactive glial cells will start to increase. Indeed, the astrocyte-to-neuron ratio has been demonstrated to increase within the SCN in AD [27]. Moreover, this ratio appears to correlate with the magnitude of circadian rhythm impairment in core body temperature and activity parameters [25]. Neuroinflammation itself has recently been implicated in the neurodegeneration process. Studies demonstrating that inflammatory mediators are highly expressed in the vicinity of amyloid plaques and NFTs, areas of high neurodegeneration [109, 110], and a clinical trial with indomethacin suggesting that conventional anti-inflammatory drugs delay the onset or slow the 
progression of $A D$ [111], substantiate this hypothesis. Albeit the latter might be due to the $A \beta 42-$ lowering effects of indomethacin itself $[112,113]$.

In mice, it has been demonstrated that neuroinflammation plays a role in the functional and molecular changes that the SCN undergoes during senescence [91]. Little evidence for neuroinflammatory processes in the SCN of AD patients is currently available. Postmortem analysis of $A D$ brains has identified $A \beta$ deposits in the hypothalamus $[114,115]$. Experiments in macaques and mice have shown that ICV infusion of $A \beta$ oligomers indeed induced hypothalamic inflammation, notably via the activation of the IKKK/NF-KB pathway [116]. Similarly, Zhang et al. reported a significant built-up of hypothalamic microglia with aging in mice. This shift in microglial population appeared to activate the IKK $\beta / N F-K B$ pathway, which facilitated cognitive decline and aging and reduced their lifespan [117]. Hypothalamic inflammation in $A D$ appears to be underexplored. Therefore, future analysis of hypothalamic neuroinflammatory markers in postmortem brains of $A D$ patients and in brains of transgenic mouse models for AD might provide new insights. Additionally, neuroinflammation of the SCN itself in the course of $A D$ is definitely worth investigating in the future.

Considering typical neuropathological hallmarks of AD, scattered NFT formation is present in the SCN. Yet, no knowledge about the exact timing of their appearance compared to that in other structures is currently available. Surprisingly, no mature neuritic plaques could be observed, even though they are abundantly present in the adjacent hypothalamus and basal ganglia [27]. The reason for this apparent resistance to plaque formation remains currently unknown. The rare diffuse plaques that are observed in the SCN resemble plaque formation in the rest of the hypothalamus, but significantly differ in their molecular and cellular composition from mature neuritic plaques in the hippocampus and neocortex, thereby suggesting a fundamental difference in pathogenesis [27]. Nevertheless, the presence of NFTs, together with the fact that neuropathological progression is associated with the severity of circadian abnormalities, provides evidence that there is a link between dysrhythmia and the central neuropathology of AD. To conclude, damage to the SCN may 
be the underlying anatomical substrate for circadian dysrhythmia often observed in association with AD pathology.

\subsection{Animal model-based evidence for the $S C N$ as initial culprit for dysrhythmia in $A D$}

\subsubsection{Lesion- and neurodegeneration-based models}

Lesions of the SCN in both laboratory animals and patients provide prove for the concept of SCN damage as the underlying substrate for circadian dysrhythmia in $A D$ described above. Clinically, patients who were diagnosed with a lesion of the SCN also showed decreased expression of vasopressin and a disturbed circadian rhythm $[118,119]$. Surgical SCN lesions in rodents do not alter the total sleep time (TST) of the animal, yet significantly affect the circadian rhythm of the sleepwake cycle in these animals [120]. SCN-lesioned rodents are more awake during the light phase, and have increased non-rapid eye movement (NREM) sleep in the dark phase. These alterations closely mimic the disturbances seen in $A D$, where both the frequency and duration of nocturnal awakenings and daytime naps are more pronounced. In the 3xTg model, an AD mouse model that displays both amyloid and tangle pathologies, an increase in the amount of time spent awake during the typically inactive phase has been demonstrated [121]. Additionally, also a decrease in activity was observed during the nocturnal active phase. Analogous to the human condition, 11-month-old mice exhibited a 27.6\% decrease in AVP-containing cells and an 18\% loss of VIP-positive neurons. Unfortunately, this study failed to demonstrate whether these changes occur prior to the occurrence of circadian disturbances. Nevertheless, damage to the SCN appears to be associated with circadian dysrhythmia. Therefore, neurodegeneration might be a reasonable explanation for the development of circadian dysrhythmia in $A D$.

\subsubsection{Toxic amyloid-beta peptide}

Another damaging process that can compromise the function of SCN in $A D$, is the presence of the toxic $A \beta$ peptide. Accumulated toxic metabolites, such as the $A \beta$ peptide, are increasingly cleared 
during sleep via the glymphatic system [122]. Conversely, wakefulness is found to be associated with an increased amyloid production [123]. Both sleep deprivation, as well as administration of the wake-promoting orexin, increase interstitial fluid (ISF) $A \beta$ and, consequently, plaque burden. In the APPswe/PS16E9 mouse model, the sleep-wake cycle markedly deteriorated and diurnal fluctuation of ISF $A \beta$ dissipated following plaque formation. Since changes in $A \beta$ dynamics occurred prior to the changes in sleep quality, and since active immunization with $A \beta 42$ prevented sleep disruption and changes in diurnal $A \beta$ fluctuations, the loss of $A \beta$ fluctuations is probably caused by changes in $A \beta$ metabolism induced by plaque formation and not by disruption of the sleep-wake cycle itself [124]. These findings indicate that amyloid pathology probably alters $A \beta$ dynamics, resulting in a disturbed sleep-wake cycle, thereby exacerbating the accumulation of toxic proteins and the progression of the pathology.

Thus, a disturbed sleep-wake cycle, as demonstrated in AD pathophysiology, will inevitably increase the amyloid burden, and therefore also negatively affect other brain functions, including SCN function. Grafting of genetically transformed cells that overexpress $A \beta$ into the $S C N$ of rats leads to significant deterioration of the circadian rhythm. Grafted rats showed unusually high levels of activity during the light phase and a disrupted circadian pattern [125]. Analogously, Syrian hamsters injected with toxic $A \beta(25-35)$ peptide into both $S C N$ exhibited a significant phase advance of the onset of running activity as compared to saline-injected animals, as well as a greater variability in this experimental parameter [126]. Again, the disturbances resulting from excessive $A \beta$ in the SCN resemble the circadian dysrhythmia often seen in patients.

In Drosophila melanogaster, pan-neuronal expression of arctic mutant human $A \beta$ has been demonstrated to cause degradation of behavioral circadian rhythms, despite preserved clock gene oscillation in central pacemaker cells. Intriguingly, $A \beta$ did not disrupt gene oscillations or behavioral rhythms when $A \beta$ expression was restricted to pigment dispersing factor neurons (central clock neuron similar to VIP positive neurons in mammals). However, if $A \beta$ was expressed in glia surrounding clock neurons, this resulted in a progressive circadian degradation [127], supporting the 
role for glial cells in modulating clock neuronal activity [128]. These findings suggest that, in an early phase, $A \beta$ probably mediates clock disruptions via circuits peripheral to the central clock neurons.

\subsubsection{The other way around: circadian dysrhythmia influences brain health}

Reversely, circadian dysrhythmia is not merely a consequence, but might also exacerbate $A D$ pathophysiology. Chronic disruption of circadian rhythms in mice housed in 20-h light/dark cycles led to reduction of dendritic length, decreased complexity of neurons in the prefrontal cortex and increased cognitive deficits [129]. Bmal1 knockout mice show disrupted circadian patterns and develop marked astrogliosis from 2 months of age, which progressed to involve the cortex, striatum and hippocampus. Moreover, oxidative damage, spontaneous degeneration of presynaptic terminals and diminished cortical activity has been demonstrated in this model [130].

To conclude, damage to the SCN might indeed underlie the development of circadian dysrhythmia. However, the molecular clock itself appears to be quite robust; and its dysfunction does not necessarily forms the initial culprit of circadian arrhythmia. Therefore, future research should try to elucidate the contribution of peripheral circuits to $A \beta$-mediated circadian dysrhythmia. Conversely, circadian dysregulation also seems to have negative implications for the brain. How these disruptions relate to the risk and progression of $A D$ still remains to be clarified.

\subsection{Pathways upstream and downstream of the SCN}

Other important factors that are able to disturb our circadian rhythm, but are often less considered, are pathways up- and downstream of the SCN. As previously stated, SCN rhythms are synchronized by photic input, mediated by retinal projections. Degeneration of the retina and the retinohypothalamic tract has been observed in AD patients $[131,132]$ and might therefore indirectly compromise SCN function. Even so, macular degeneration and cataract are often noted in the elderly and appear to influence the risk for $A D$ [133]. In addition, clinical studies have demonstrated an 
increased prevalence of glaucoma in $A D[134,135]$. The slow progressive degeneration of retinal ganglion cells and axons in the optic nerve that characterizes this disease are hypothesized to be a result of suppressed glymphatic fluid transport (due to e.g., lower intracranial pressure) $[136,137]$. Thus, even less obvious phenomena that occur in the course of $A D$, might somehow indirectly compromise SCN function.

Secondly, the cholinergic basal forebrain undergoes extensive degeneration in AD [138]. Destruction of the nucleus basalis of Meynert impairs AVP and VIP neuropeptide synthesis [139]. Moreover, the SCN receives cholinergic projections from the basal forebrain, which potentially modulate the sensitivity of the circadian clock to the phase advancing effects of light. Erhardt et al. demonstrated that lesioning of these cholinergic projections via ICV and intra-SCN injections of the immunotoxin 192 IgG-saporin reduced light-induced phase advances and increased phase delays [140]. However, a similar study, in which the medial septum was lesioned using 192 IgG-saporin as well, failed to establish these results. Craig and others indeed found that cholinergic depletion did not result in an increased susceptibility to circadian disruption, nor contributed to learning and memory deficits [141]. Future research on the effects of cholinergic degeneration on circadian rhythmicity is called for, because current studies still remain inconclusive $[140,141]$. In addition, acetylcholinesterase inhibitors (AChEI) are often recommended in the management of mild to moderately severe $A D$, even though these therapeutic strategies mostly only have a positive cognitive effect during diurnal hours. Donepezil for example, induces a stable increase of ACh for more than 24 hours, and therefore interferes with the physiological dip in ACh during SWS [142]. By consequence, donepezil can exacerbate sleep disorders and create adverse sleep-related events [143]. Although the type and formulation of the drug and the timing of administration are of crucial importance in the optimization of cholinergic treatment in AD patients, we would like to emphasize that AChEl therapy should be approached with caution and that more studies are needed to elaborate the effects of these drugs on the mechanisms linking our sleep and circadian systems with brain health. 
Thirdly, dysfunction of the melatonin system has been implicated in the development of circadian dysrhythmia in AD. Melatonin secretion and levels of the melatonin receptor 1, which are implicated in the feedback role of melatonin on SCN rhythmicity, are strongly reduced in aging [144], and even more so in $\operatorname{AD}[145,146]$. Since these reduced circadian effects of melatonin might contribute to clinical circadian disorders, melatonin supplementation has been suggested as a therapeutic measure. However, the effect of this treatment remains doubtful [147-150].

Finally, decreases in external zeitgebers might also contribute to the etiology of circadian dysrhythmia. Exposure of the eyes to sufficient light at the appropriate time of day is essential for the quality, duration, and timing of sleep $[18,151]$. Even so, exercise is a sufficient environmental cue to effect clock gene expression in the SCN [152]. After institutionalization, patients are often not exposed to appropriately timed and sufficiently high lights levels have a sedentary lifestyle, and thereby lose entrainment to the 24-hour day/night cycle [153]. Ultimately, this loss of entrainment might influence the progression of the disease. Bright light therapy has proven to be an effective therapeutic strategy for sleep-activity disruption in institutionalized $A D$ patients by improving nighttime sleep and decreasing daytime sleepiness $[154,155]$. Recent evidence suggest that, instead of continuous light exposures, repeated intermittent light stimulations in the order of milliseconds are equally or more efficient in changing the phase of the circadian system [156]. As these flashes are able to modulate the circadian system while asleep, when the eyelids are closed, and without affecting sleep, these therapeutic strategies are especially of interest for $A D$ patients. Most institutionalized patients feel agitated and are not very cooperative during long sensory stimulation interventions. Since exercise programs may also help to positively alter SCN functioning, such behavioral therapies, in addition to light therapy, should also be considered henceforth. To improve the quality of life of patients and caregivers the combination of existing therapeutic strategies is an interesting approach. For example, combination therapy of bright light in conjunction with melatonin 
holds promising results, because bright light therapy diminishes the adverse effects that melatonin can have on mood [157]. Also the development of new chronotherapeutics is essential. Directly targeting the main circadian pacemaker might hold promising results for future research.

\section{Concluding remarks and future perspectives}

Circadian dysrhythmia and associated sleep disturbances are common symptoms in AD and have a significant impact on both patients and caregivers. Considerable evidence suggests that the SCN is involved in the development of these symptoms. Future research is needed to further elucidate the reciprocal relation between $S C N$ disruption and $A D$ pathophysiology and to identify new therapeutic targets that may improve the function of the central pacemaker. Both behavioral and pharmacological approaches should be further explored. Especially a combination of these therapies might hold promise for the future. Furthermore, fundamental research of clock gene function and SCN electrophysiological properties in the context of $A D$ is recommended in the future. $A$ better understanding of the clock gene function might identify new small molecule modulators of clock oscillation that can alter the amplitude, period and frequency of SCN output. The study of electrophysiological properties could provide useful insights about deep brain stimulation, and eventually perhaps also optogenetics, as possible therapeutic options. Similar to the cardiac pacemaker, pacing the $\mathrm{SCN}$ via deep brain stimulation might restore the physiological rhythm and thereby improve circadian rhythmicity in AD patients.

In conclusion, the true nature of circadian disruption in $A D$ still remains to be elucidated. As amelioration of circadian disruption is likely to increase the self-care ability of AD patients and reduce the institutionalization rate, this line of research deserves further and increased focus by the research community. We would like to emphasize that further elucidation of clock (dys)function and the development of new chronotherapeutics are of essential importance to improve the life quality of patients and caregivers. 


\section{Practice points}

1 Circadian dysrhythmia is a common symptom in AD patients, which immensely decreases the self-care ability of AD-patients and forms one of the main reasons of caregiver exhaustion.

2 During aging, and even more so in the course of $A D$, the suprachiasmatic nucleus is subjected to neurodegeneration.

3 Neurodegeneration of the suprachiasmatic nucleus has also been demonstrated in the $3 \times \mathrm{Tg}$ model for AD.

4 Several neuropeptides are responsible for the generation and modulation of the circadian rhythm and a loss of their function could be a culprit of circadian disorders.

5 The involvement of neuroinflammation in the development of circadian dysrhythmia remains quite unclear up until now.

6 The suprachiasmatic nucleus appears to be resistant to plaque formation in AD patients, yet the involvement of the toxic amyloid-beta peptide remains unclear.

7 In animal models, the presence of the toxic amyloid-beta peptide in the suprachiasmatic nucleus induced circadian dysrhythmia.

\section{Research agenda}

1 Further investigating alterations in membrane properties, neurotransmitter levels, or dendritic and synaptic contacts in the SCN, since neurodegeneration might only be an end-stage phenomenon.

2 Clarifying the role of hypothalamic inflammation in the development of circadian disturbances.

3 Studying the SCN electrical activity in both patients and animal models for AD, which might provide new insights into the development of circadian dysrhythmia.

4 Establishing the involvement of pathways up- and downstream of the SCN. 


\section{References}

[1] Prince M, Wimo AGM, Ali GC, Wu YT, Prina M. World Alzheimer Report 2015. The Global Impact of Dementia. An Analysis of Prevalence, Incidence, Cost and Trends. London: Alzheimer's Disease International. 2015.

[2] Qiu C, Kivipelto M, von Strauss E. Epidemiology of Alzheimer's disease: occurrence, determinants, and strategies toward intervention. Dialogues in Clinical Neuroscience. 2009;11(2):111-28.

[3] Selkoe DJ. Cell biology of protein misfolding: The examples of Alzheimer's and Parkinson's diseases. Nat Cell Biol. 2004;6(11):1054-61.

[4] Brion JP. Neurofibrillary tangles and Alzheimer's disease. European neurology. 1998;40(3):13040.

[5] Hardy J, Allsop D. Amyloid deposition as the central event in the aetiology of Alzheimer's disease. Trends in pharmacological sciences. 1991;12(10):383-8.

[6] Ghiso J, Tomidokoro Y, Revesz T, Frangione B, Rostagno A. Cerebral amyloid angiopathy and Alzheimer's disease. Hirosaki igaku = Hirosaki medical journal. 2010;61(Suppl):S111-S24.

[7] Van Dam D, De Deyn PP. Animal models in the drug discovery pipeline for Alzheimer's disease. British journal of pharmacology. 2011;164(4):1285-300.

[8] Lyketsos CG, Lopez O, Jones B, Fitzpatrick AL, Breitner J, DeKosky S. Prevalence of neuropsychiatric symptoms in dementia and mild cognitive impairment: results from the cardiovascular health study. Jama. 2002;288(12):1475-83.

[9] Van der Mussele S, Le Bastard N, Vermeiren Y, Saerens J, Somers N, Marien P, et al. Behavioral symptoms in mild cognitive impairment as compared with Alzheimer's disease and healthy older adults. International journal of geriatric psychiatry. 2013;28(3):265-75.

[10] Vermeiren Y, Van Dam D, Aerts T, Engelborghs S, De Deyn PP. Brain region-specific monoaminergic correlates of neuropsychiatric symptoms in Alzheimer's disease. Journal of Alzheimer's disease : JAD. 2014;41(3):819-33.

[11] Van Dam D, Vermeiren Y, Dekker AD, Naude PJ, De Deyn PP. Neuropsychiatric disturbances in Alzheimer's disease: what have we learned from neuropathological studies? Current Alzheimer research. 2016.

[12] Finkel SI, Costa e Silva J, Cohen G, Miller S, Sartorius N. Behavioral and Psychological Signs and Symptoms of Dementia: A Consensus Statement on Current Knowledge and Implications for Research and Treatment. International Psychogeriatrics. 1997;8(SupplementS3):497-500.

[13] Reisberg B, Borenstein J, Salob SP, Ferris SH, Franssen E, Georgotas A. Behavioral symptoms in Alzheimer's disease: phenomenology and treatment. The Journal of clinical psychiatry. 1987;48 Suppl:9-15.

[14] Moran M, Lynch CA, Walsh C, Coen R, Coakley D, Lawlor BA. Sleep disturbance in mild to moderate Alzheimer's disease. Sleep medicine. 2005;6(4):347-52.

[15] Beaulieu-Bonneau S, Hudon C. Sleep disturbances in older adults with mild cognitive impairment. International psychogeriatrics / IPA. 2009;21(4):654-66.

[16] Hatfield CF, Herbert J, van Someren EJ, Hodges JR, Hastings MH. Disrupted daily activity/rest cycles in relation to daily cortisol rhythms of home-dwelling patients with early Alzheimer's dementia. Brain : a journal of neurology. 2004;127(Pt 5):1061-74.

[17] Prinz PN, Peskind ER, Vitaliano PP, Raskind MA, Eisdorfer C, Zemcuznikov HN, et al. Changes in the Sleep and Waking EEGs of Nondemented and Demented Elderly Subjects. Journal of the American Geriatrics Society. 1982;30(2):86-92.

[18] Bliwise DL, Hughes M, McMahon PM, Kutner N. Observed sleep/wakefulness and severity of dementia in an Alzheimer's disease special care unit. The journals of gerontology Series A, Biological sciences and medical sciences. 1995;50(6):M303-6.

[19] Witting W, Kwa IH, Eikelenboom P, Mirmiran M, Swaab DF. Alterations in the circadian restactivity rhythm in aging and Alzheimer's disease. Biological psychiatry. 1990;27(6):563-72.

[20] Huang YL, Liu RY, Wang QS, Van Someren EJ, Xu H, Zhou JN. Age-associated difference in circadian sleep-wake and rest-activity rhythms. Physiology \& behavior. 2002;76(4-5):597-603. 
[21] McCurry SM, Logsdon RG, Teri L, Gibbons LE, Kukull WA, Bowen JD, et al. Characteristics of sleep disturbance in community-dwelling Alzheimer's disease patients. Journal of geriatric psychiatry and neurology. 1999;12(2):53-9.

[22] Prinz PN, Vitiello MV, Raskind MA, Thorpy MJ. Geriatrics: sleep disorders and aging. The New England journal of medicine. 1990;323(8):520-6.

[23] Moe KE, Vitiello MV, Larsen LH, Prinz PN. Symposium: Cognitive processes and sleep disturbances: Sleep/wake patterns in Alzheimer's disease: relationships with cognition and function. Journal of sleep research. 1995;4(1):15-20.

[24] Pollak CP, Perlick D. Sleep problems and institutionalization of the elderly. Journal of geriatric psychiatry and neurology. 1991;4(4):204-10.

[25] Harper DG, Stopa EG, Kuo-Leblanc V, McKee AC, Asayama K, Volicer L, et al. Dorsomedial SCN neuronal subpopulations subserve different functions in human dementia. Brain : a journal of neurology. 2008;131(Pt 6):1609-17.

[26] Skene DJ, Swaab DF. Melatonin rhythmicity: effect of age and Alzheimer's disease. Experimental gerontology. 2003;38(1-2):199-206.

[27] Stopa EG, Volicer L, Kuo-Leblanc V, Harper D, Lathi D, Tate B, et al. Pathologic evaluation of the human suprachiasmatic nucleus in severe dementia. Journal of neuropathology and experimental neurology. 1999;58(1):29-39.

[28] Swaab DF, Fliers E, Partiman TS. The suprachiasmatic nucleus of the human brain in relation to sex, age and senile dementia. Brain research. 1985;342(1):37-44.

[29] Tranah GJ, Blackwell T, Stone KL, Ancoli-Israel S, Paudel ML, Ensrud KE, et al. Circadian activity rhythms and risk of incident dementia and mild cognitive impairment in older women. Annals of neurology. 2011;70(5):722-32.

[30] Ukai H, Ueda HR. Systems biology of mammalian circadian clocks. Annual review of physiology. 2010;72:579-603.

[31] Aguilar-Roblero R, Drucker-Colin R, Moore RY. Behavioral and morphological studies of fetal neural transplants into SCN-lesioned rats. Chronobiology international. 1992;9(4):278-96.

[32] DeCoursey PJ, Buggy J. Circadian rhythmicity after neural transplant to hamster third ventricle: specificity of suprachiasmatic nuclei. Brain research. 1989;500(1-2):263-75.

[33] Lehman MN, Silver R, Gladstone WR, Kahn RM, Gibson M, Bittman EL. Circadian rhythmicity restored by neural transplant. Immunocytochemical characterization of the graft and its integration with the host brain. The Journal of neuroscience : the official journal of the Society for Neuroscience. 1987;7(6):1626-38.

*[34] Ralph MR, Foster RG, Davis FC, Menaker M. Transplanted suprachiasmatic nucleus determines circadian period. Science (New York, NY). 1990;247(4945):975-8.

[35] Abrahamson EE, Moore RY. Suprachiasmatic nucleus in the mouse: retinal innervation, intrinsic organization and efferent projections. Brain research. 2001;916(1-2):172-91.

[36] Groblewski TA, Nunez AA, Gold RM. Circadian rhythms in vasopressin deficient rats. Brain research bulletin. 1981;6(2):125-30.

[37] Stoinev AG, Ikonomov O. Effects of continuous infusion of vasopressin on circadian rhythms of food and water intake, urine output and electrolyte excretion in Brattleboro rats. Biulleten' eksperimental'noi biologii i meditsiny. 1990;109(2):109-11.

[38] Brown MH, Nunez AA. Vasopressin-deficient rats show a reduced amplitude of the circadian sleep rhythm. Physiology \& behavior. 1989;46(4):759-62.

[39] Aton SJ, Colwell CS, Harmar AJ, Waschek J, Herzog ED. Vasoactive intestinal polypeptide mediates circadian rhythmicity and synchrony in mammalian clock neurons. Nature neuroscience. 2005;8(4):476-83.

[40] Coogan AN, Rawlings N, Luckman SM, Piggins HD. Effects of neurotensin on discharge rates of rat suprachiasmatic nucleus neurons in vitro. Neuroscience. 2001;103(3):663-72.

[41] Meyer-Spasche A, Reed HE, Piggins HD. Neurotensin phase-shifts the firing rate rhythm of neurons in the rat suprachiasmatic nuclei in vitro. The European journal of neuroscience.

2002;16(2):339-44. 
[42] Alexander MJ, Leeman SE. Widespread expression in adult rat forebrain of mRNA encoding high-affinity neurotensin receptor. The Journal of comparative neurology. 1998;402(4):475-500.

[43] Boudin H, Pelaprat D, Rostene W, Beaudet A. Cellular distribution of neurotensin receptors in rat brain: immunohistochemical study using an antipeptide antibody against the cloned high affinity receptor. The Journal of comparative neurology. 1996;373(1):76-89.

[44] Francois-Bellan AM, Bosler O, Tonon MC, Wei LT, Beaudet A. Association of neurotensin receptors with VIP-containing neurons and serotonin-containing axons in the suprachiasmatic nucleus of the rat. Synapse (New York, NY). 1992;10(4):282-90.

[45] Hendrickson AE, Wagoner N, Cowan WM. An autoradiographic and electron microscopic study of retino-hypothalamic connections. Zeitschrift fur Zellforschung und mikroskopische Anatomie (Vienna, Austria : 1948). 1972;135(1):1-26.

[46] Moore RY, Lenn NJ. A retinohypothalamic projection in the rat. The Journal of comparative neurology. 1972;146(1):1-14.

[47] Mistlberger RE, Skene DJ. Nonphotic entrainment in humans? Journal of biological rhythms. 2005;20(4):339-52.

[48] Sack RL, Lewy AJ, Blood ML, Keith LD, Nakagawa H. Circadian rhythm abnormalities in totally blind people: incidence and clinical significance. The Journal of Clinical Endocrinology \& Metabolism. 1992;75(1):127-34.

[49] Gekakis N, Staknis D, Nguyen HB, Davis FC, Wilsbacher LD, King DP, et al. Role of the CLOCK protein in the mammalian circadian mechanism. Science (New York, NY). 1998;280(5369):1564-9.

[50] Akashi M, Tsuchiya Y, Yoshino T, Nishida E. Control of intracellular dynamics of mammalian period proteins by casein kinase I epsilon (CKlepsilon) and CKIdelta in cultured cells. Molecular and cellular biology. 2002;22(6):1693-703.

[51] Langmesser S, Tallone T, Bordon A, Rusconi S, Albrecht U. Interaction of circadian clock proteins PER2 and CRY with BMAL1 and CLOCK. BMC Molecular Biology. 2008;9(1):1-16.

[52] Fu L, Lee CC. The circadian clock: pacemaker and tumour suppressor. Nat Rev Cancer. 2003;3(5):350-61.

[53] Guillaumond F, Dardente H, Giguere V, Cermakian N. Differential control of Bmal1 circadian transcription by REV-ERB and ROR nuclear receptors. Journal of biological rhythms. 2005;20(5):391403.

[54] Kwon I, Lee J, Chang SH, Jung NC, Lee BJ, Son GH, et al. BMAL1 Shuttling Controls Transactivation and Degradation of the CLOCK/BMAL1 Heterodimer. Molecular and cellular biology. 2006;26(19):7318-30.

[55] Gerstner JR, Yin JC. Circadian rhythms and memory formation. Nature reviews Neuroscience. 2010;11(8):577-88.

[56] Hasegawa K, Saigusa T, Tamai Y. Caenorhabditis elegans opens up new insights into circadian clock mechanisms. Chronobiology international. 2005;22(1):1-19.

[57] Laposky A, Easton A, Dugovic C, Walisser J, Bradfield C, Turek F. Deletion of the mammalian circadian clock gene BMAL1/Mop3 alters baseline sleep architecture and the response to sleep deprivation. Sleep. 2005;28(4):395-409.

[58] Shiromani PJ, Xu M, Winston EM, Shiromani SN, Gerashchenko D, Weaver DR. Sleep rhythmicity and homeostasis in mice with targeted disruption of mPeriod genes. American Journal of Physiology Regulatory, Integrative and Comparative Physiology. 2004;287(1):R47-R57.

[59] Wisor JP, O'Hara BF, Terao A, Selby CP, Kilduff TS, Sancar A, et al. A role for cryptochromesin sleep regulation. BMC Neuroscience. 2002;3(1):1-14.

[60] Welsh DK, Takahashi JS, Kay SA. Suprachiasmatic Nucleus: Cell Autonomy and Network Properties. Annual review of physiology. 2010;72:551-77.

[61] Abrahamson EE, Leak RK, Moore RY. The suprachiasmatic nucleus projects to posterior hypothalamic arousal systems. NeuroReport. 2001;12(2).

[62] Buijs RM, van Eden CG, Goncharuk VD, Kalsbeek A. The biological clock tunes the organs of the body: timing by hormones and the autonomic nervous system. Journal of Endocrinology.

2003;177(1):17-26. 
[63] Dai J, Swaab DF, Buijs RM. Distribution of vasopressin and vasoactive intestinal polypeptide (VIP) fibers in the human hypothalamus with special emphasis on suprachiasmatic nucleus efferent projections. The Journal of comparative neurology. 1997;383(4):397-414.

[64] Deurveilher S, Semba K. Indirect projections from the suprachiasmatic nucleus to major arousalpromoting cell groups in rat: Implications for the circadian control of behavioural state.

Neuroscience. 2005;130(1):165-83.

[65] Kriegsfeld LJ, Leak RK, Yackulic CB, LeSauter J, Silver RAE. Organization of Suprachiasmatic Nucleus Projections in Syrian Hamsters (Mesocricetus auratus): An Anterograde and Retrograde Analysis. The Journal of comparative neurology. 2004;468(3):361-79.

[66] Saper CB, Lu J, Chou TC, Gooley J. The hypothalamic integrator for circadian rhythms. Trends in Neurosciences. 2005;28(3):152-7.

[67] Watts AG, Swanson LW. Efferent projections of the suprachiasmatic nucleus: II. Studies using retrograde transport of fluorescent dyes and simultaneous peptide immunohistochemistry in the rat. The Journal of comparative neurology. 1987;258(2):230-52.

[68] Watts AG, Swanson LW, Sanchez-Watts G. Efferent projections of the suprachiasmatic nucleus: I. Studies using anterograde transport of Phaseolus vulgaris leucoagglutinin in the rat. The Journal of comparative neurology. 1987;258(2):204-29.

[69] Franklin KBJ, Paxinos G. The mouse brain in stereotactic coordinates. 2008.

[70] Lu J, Zhang YH, Chou TC, Gaus SE, Elmquist JK, Shiromani P, et al. Contrasting Effects of Ibotenate Lesions of the Paraventricular Nucleus and Subparaventricular Zone on Sleep-Wake Cycle and Temperature Regulation. The Journal of neuroscience : the official journal of the Society for Neuroscience. 2001;21(13):4864-74.

[71] Chou TC, Bjorkum AA, Gaus SE, Lu J, Scammell TE, Saper CB. Afferents to the Ventrolateral Preoptic Nucleus. The Journal of Neuroscience. 2002;22(3):977.

[72] Chou TC, Scammell TE, Gooley JJ, Gaus SE, Saper CB, Lu J. Critical Role of Dorsomedial Hypothalamic Nucleus in a Wide Range of Behavioral Circadian Rhythms. The Journal of Neuroscience. 2003;23(33):10691-702.

[73] Thompson RH, Canteras NS, Swanson LW. Organization of projections from the dorsomedial nucleus of the hypothalamus: A PHA-L study in the rat. The Journal of comparative neurology. 1996;376(1):143-73.

[74] Moore RY. Neural control of the pineal gland. Behavioural brain research. 1996;73(1-2):125-30. [75] Castel M, Morris JF. Morphological heterogeneity of the GABAergic network in the suprachiasmatic nucleus, the brain's circadian pacemaker. Journal of Anatomy. 2000;196(Pt 1):1-13.

[76] Csáki A, Kocsis K, Halász B, Kiss J. Localization of glutamatergic/aspartatergic neurons projecting to the hypothalamic paraventricular nucleus studied by retrograde transport of [3H]D-aspartate autoradiography. Neuroscience. 2000;101(3):637-55.

[77] Cui L-N, Coderre E, Renaud LP. Glutamate and GABA mediate suprachiasmatic nucleus inputs to spinal-projecting paraventricular neurons. American Journal of Physiology - Regulatory, Integrative and Comparative Physiology. 2001;281(4):R1283.

[78] Kalsbeek A, Garidou M-L, Palm IF, Van Der Vliet J, Simonneaux V, Pévet P, et al. Melatonin sees the light: blocking GABA-ergic transmission in the paraventricular nucleus induces daytime secretion of melatonin. European Journal of Neuroscience. 2000;12(9):3146-54.

[79] Perreau-Lenz S, Kalsbeek A, Pévet P, Buijs RM. Glutamatergic clock output stimulates melatonin synthesis at night. European Journal of Neuroscience. 2004;19(2):318-24.

[80] Kalsbeek A, La Fleur S, Van Heijningen C, Buijs RM. Suprachiasmatic GABAergic Inputs to the Paraventricular Nucleus Control Plasma Glucose Concentrations in the Rat via Sympathetic Innervation of the Liver. The Journal of Neuroscience. 2004;24(35):7604.

[81] Liu C, Weaver DR, Jin X, Shearman LP, Pieschl RL, Gribkoff VK, et al. Molecular Dissection of Two Distinct Actions of Melatonin on the Suprachiasmatic Circadian Clock. Neuron. 1997;19(1):91-102.

[82] Silver R, LeSauter J, Tresco PA, Lehman MN. A diffusible coupling signal from the transplanted suprachiasmatic nucleus controlling circadian locomotor rhythms. Nature. 1996;382(6594):810-3. 
[83] Kramer A, Yang F-C, Snodgrass P, Li X, Scammell TE, Davis FC, et al. Regulation of Daily Locomotor Activity and Sleep by Hypothalamic EGF Receptor Signaling. Science (New York, NY). 2001;294(5551):2511.

[84] Cheng MY, Bullock CM, Li C, Lee AG, Bermak JC, Belluzzi J, et al. Prokineticin 2 transmits the behavioural circadian rhythm of the suprachiasmatic nucleus. Nature. 2002;417(6887):405-10. [85] Inouye ST, Kawamura H. Characteristics of a circadian pacemaker in the suprachiasmatic nucleus. J Comp Physiol. 1982;146(2):153-60.

* [86] Inouye ST, Kawamura H. Persistence of circadian rhythmicity in a mammalian hypothalamic "island" containing the suprachiasmatic nucleus. Proceedings of the National Academy of Sciences of the United States of America. 1979;76(11):5962-6.

*[87] Sato T, Kawamura H. Circadian rhythms in multiple unit activity inside and outside the suprachiasmatic nucleus in the diurnal chipmunk (Eutamias sibiricus). Neuroscience research. 1984;1(1):45-52.

[88] Yamazaki S, Kerbeshian MC, Hocker CG, Block GD, Menaker M. Rhythmic properties of the hamster suprachiasmatic nucleus in vivo. The Journal of neuroscience : the official journal of the Society for Neuroscience. 1998;18(24):10709-23.

[89] Novak CM, Ehlen JC, Paul KN, Fukuhara C, Albers HE. Light and GABAA receptor activation alter Period mRNA levels in the SCN of diurnal Nile grass rats. European Journal of Neuroscience. 2006;24(10):2843-52.

[90] Nygard M, Hill RH, Wikstrom MA, Kristensson K. Age-related changes in electrophysiological properties of the mouse suprachiasmatic nucleus in vitro. Brain research bulletin. 2005;65(2):149-54. [91] Bentivoglio $M$, Deng XH, Nygård M, Sadki A, Kristensson K. The aging suprachiasmatic nucleus and cytokines: functional, molecular, and cellular changes in rodents. Chronobiology international. 2006;23(1-2):437-49.

*[92] Hurd MW, Ralph MR. The Significance of Circadian Organization for Longevity in the Golden Hamster. Journal of biological rhythms. 1998;13(5):430-6.

[93] Li H, Satinoff E. Fetal tissue containing the suprachiasmatic nucleus restores multiple circadian rhythms in old rats. The American journal of physiology. 1998;275(6 Pt 2):R1735-44.

[94] Madeira MD, Sousa N, Santer RM, Paula-Barbosa MM, Gundersen HJ. Age and sex do not affect the volume, cell numbers, or cell size of the suprachiasmatic nucleus of the rat: an unbiased stereological study. The Journal of comparative neurology. 1995;361(4):585-601.

[95] Tsukahara S, Tanaka S, Ishida K, Hoshi N, Kitagawa H. Age-related change and its sex differences in histoarchitecture of the hypothalamic suprachiasmatic nucleus of $\mathrm{F} 344 / \mathrm{N}$ rats. Experimental gerontology. 2005;40(3):147-55.

[96] Roberts DE, Killiany RJ, Rosene DL. Neuron Numbers in the Hypothalamus of the Normal Aging Rhesus Monkey: Stability Across the Adult Lifespan and Between the Sexes. The Journal of comparative neurology. 2012;520(6):1181-97.

[97] Angelie E, Bonmartin A, Boudraa A, Gonnaud PM, Mallet JJ, Sappey-Marinier D. Regional differences and metabolic changes in normal aging of the human brain: proton MR spectroscopic imaging study. AJNR American journal of neuroradiology. 2001;22(1):119-27.

[98] Lu T, Pan Y, Kao S-Y, Li C, Kohane I, Chan J, et al. Gene regulation and DNA damage in the ageing human brain. Nature. 2004;429(6994):883-91.

[99] Ohyama H, Hiramatsu M, Ogawa N, Mori A. Age-related differences in synaptosomal membrane fluidity. Biochemistry and molecular biology international. 1995;37(1):133-40.

[100] Eckert GP, Cairns NJ, Maras A, Gattaz WF, Muller WE. Cholesterol modulates the membranedisordering effects of beta-amyloid peptides in the hippocampus: specific changes in Alzheimer's disease. Dementia and geriatric cognitive disorders. 2000;11(4):181-6.

[101] Nagy K, Nagy V, Bertoni-Freddari C, Nagy I. Alterations of the synaptosomal membrane 'microviscosity' in the brain cortex of rats during aging and centrophenoxine treatment. Archives of gerontology and geriatrics. 1983;2(1-2):23-39.

[102] Carmena MJ, Hueso C, Guijarro LG, Prieto JC. Cholesterol modulation of membrane fluidity and VIP receptor/effector system in rat prostatic epithelial cells. Regulatory Peptides. 1991;33(3):287-97. 
[103] Scheuer K, Stoll S, Paschke U, Weigel R, Muller WE. N-methyl-D-aspartate receptor density and membrane fluidity as possible determinants of the decline of passive avoidance performance in aging. Pharmacology, biochemistry, and behavior. 1995;50(1):65-70.

[104] Zhou J-N, Swaab DF. Activation and degeneration during aging: A morphometric study of the human hypothalamus. Microscopy Research and Technique. 1999;44(1):36-48.

[105] Hofman MA, Swaab DF. Alterations in circadian rhythmicity of the vasopressin-producing neurons of the human suprachiasmatic nucleus (SCN) with aging. Brain research. 1994;651(1-2):13442.

[106] Farajnia S, Michel S, Deboer T, vanderLeest HT, Houben T, Rohling JH, et al. Evidence for neuronal desynchrony in the aged suprachiasmatic nucleus clock. The Journal of neuroscience : the official journal of the Society for Neuroscience. 2012;32(17):5891-9.

[107] Liu RY, Zhou JN, Hoogendijk WJ, van Heerikhuize J, Kamphorst W, Unmehopa UA, et al.

Decreased vasopressin gene expression in the biological clock of Alzheimer disease patients with and without depression. Journal of neuropathology and experimental neurology. 2000;59(4):314-22.

[108] Zhou JN, Hofman MA, Swaab DF. VIP neurons in the human SCN in relation to sex, age, and Alzheimer's disease. Neurobiol Aging. 1995;16(4):571-6.

[109] Akiyama H, Barger S, Barnum S, Bradt B, Bauer J, Cole GM, et al. Inflammation and Alzheimer's disease. Neurobiology of aging. 2000;21(3):383-421.

[110] Yin Z, Raj D, Saiepour N, Van Dam D, Brouwer N, Holtman IR, et al. Immune hyperreactivity of $A \beta$ plaque-associated microglia in Alzheimer's disease. Neurobiology of Aging. 2017.

[111] Rogers J, Kirby LC, Hempelman SR, Berry DL, McGeer PL, Kaszniak AW, et al. Clinical trial of indomethacin in Alzheimer's disease. Neurology. 1993;43(8):1609-.

[112] Quinn J, Montine T, Morrow J, Woodward WR, Kulhanek D, Eckenstein F. Inflammation and cerebral amyloidosis are disconnected in an animal model of Alzheimer's disease. Journal of Neuroimmunology. 2003;137(1):32-41.

[113] Weggen S, Eriksen JL, Das P, Sagi SA, Wang R, Pietrzik CU, et al. A subset of NSAIDs lower amyloidogenic $A \beta 42$ independently of cyclooxygenase activity. Nature. 2001;414(6860):212-6.

[114] Ogomori K, Kitamoto T, Tateishi J, Sato Y, Suetsugu M, Abe M. Beta-protein amyloid is widely distributed in the central nervous system of patients with Alzheimer's disease. The American journal of pathology. 1989;134(2):243-51.

[115] Standaert DG, Lee VM, Greenberg BD, Lowery DE, Trojanowski JQ. Molecular features of hypothalamic plaques in Alzheimer's disease. The American journal of pathology. 1991;139(3):68191.

[116] Purkayastha S, Cai D. Disruption of Neurogenesis by Hypothalamic Inflammation in Obesity or Aging. Reviews in endocrine \& metabolic disorders. 2013;14(4):10.1007/s11154-013-9279-z.

[117] Zhang G, Li J, Purkayastha S, Tang Y, Zhang H, Yin Y, et al. Hypothalamic Programming of Systemic Aging Involving IKKß/NF-KB and GnRH. Nature. 2013;497(7448):211-6.

[118] Cohen RA, Albers EH. Disruption of human circadian and cognitive regulation following a discrete hypothalamic lesion: A case study. Neurology. 1991;41(5):726-9.

[119] Schwartz W, Busis N, Tessa Hedley-Whyte E. A discrete lesion of ventral hypothalamus and optic chiasm that disturbed the daily temperature rhythm. J Neurol. 1986;233(1):1-4.

*[120] Liu X-G, Zhang B-J, Xu X-H, Huang Z-L, Qu W-M. Lesions of suprachiasmatic nucleus modify sleep structure but do not alter the total amount of daily sleep in rats. Sleep and Biological Rhythms. 2012;10(4):293-301.

*[121] Sterniczuk R, Dyck RH, Laferla FM, Antle MC. Characterization of the 3xTg-AD mouse model of Alzheimer's disease: part 1. Circadian changes. Brain research. 2010;1348:139-48.

*[122] Xie L, Kang H, Xu Q, Chen MJ, Liao Y, Thiyagarajan M, et al. Sleep drives metabolite clearance from the adult brain. Science (New York, NY). 2013;342(6156):373-7.

[123] Kang JE, Lim MM, Bateman RJ, Lee JJ, Smyth LP, Cirrito JR, et al. Amyloid-beta dynamics are regulated by orexin and the sleep-wake cycle. Science (New York, NY). 2009;326(5955):1005-7. 
[124] Roh JH, Huang Y, Bero AW, Kasten T, Stewart FR, Bateman RJ, et al. Disruption of the sleepwake cycle and diurnal fluctuation of beta-amyloid in mice with Alzheimer's disease pathology. Science translational medicine. 2012;4(150):150ra22.

*[125] Tate B, Aboody-Guterman KS, Morris AM, Walcott EC, Majocha RE, Marotta CA. Disruption of circadian regulation by brain grafts that overexpress Alzheimer beta/A4 amyloid. Proceedings of the National Academy of Sciences of the United States of America. 1992;89(15):7090-4.

[126] Furio AM, Cutrera RA, Thea VC, Lloret SP, Riccio P, Caccuri RL, et al. Effect of Melatonin on Changes in Locomotor Activity Rhythm of Syrian Hamsters Injected with Beta Amyloid Peptide 25-35 in the Suprachiasmatic Nuclei. Cellular and Molecular Neurobiology. 2002;22(5):699-709.

*[127] Chen KF, Possidente B, Lomas DA, Crowther DC. The central molecular clock is robust in the face of behavioural arrhythmia in a Drosophila model of Alzheimer's disease. Disease models \& mechanisms. 2014;7(4):445-58.

[128] Ng FS, Tangredi MM, Jackson FR. Glial cells physiologically modulate clock neurons and circadian behavior in a calcium-dependent manner. Curr Biol. 2011;21(8):625-34.

[129] Karatsoreos IN, Bhagat S, Bloss EB, Morrison JH, McEwen BS. Disruption of circadian clocks has ramifications for metabolism, brain, and behavior. Proceedings of the National Academy of Sciences. 2011;108(4):1657-62.

[130] Musiek ES, Lim MM, Yang G, Bauer AQ, Qi L, Lee Y, et al. Circadian clock proteins regulate neuronal redox homeostasis and neurodegeneration. The Journal of clinical investigation.

2013;123(12):5389-400.

[131] Katz B, Rimmer S, Iragui V, Katzman R. Abnormal pattern electroretinogram in Alzheimer's disease: Evidence for retinal ganglion cell degeneration? Annals of neurology. 1989;26(2):221-5.

[132] Hinton DR, Sadun AA, Blanks JC, Miller CA. Optic-nerve degeneration in Alzheimer's disease. The New England journal of medicine. 1986;315(8):485-7.

[133] Klaver CC, Ott A, Hofman A, Assink JJ, Breteler MM, de Jong PT. Is age-related maculopathy associated with Alzheimer's Disease? The Rotterdam Study. American journal of epidemiology. 1999;150(9):963-8.

[134] Bayer AU, Ferrari F, Erb C. High Occurrence Rate of Glaucoma among Patients with Alzheimer's Disease. European neurology. 2002;47(3):165-8.

[135] Tamura H, Kawakami H, Kanamoto T, Kato T, Yokoyama T, Sasaki K, et al. High frequency of open-angle glaucoma in Japanese patients with Alzheimer's disease. Journal of the Neurological Sciences. 2006;246(1-2):79-83.

[136] Wostyn P, Audenaert K, De Deyn PP. Alzheimer's disease and glaucoma: Is there a causal relationship? British Journal of Ophthalmology. 2009;93(12):1557.

[137] Wostyn P, De Groot V, Van Dam D, Audenaert K, Killer HE, De Deyn PP. Alzheimer's disease and glaucoma: can glymphatic system dysfunction underlie their comorbidity? Acta Ophthalmologica. 2017;95(3):e244-e5.

[138] Mott RT, Hulette CM. Neuropathology of Alzheimer's disease. Neuroimaging clinics of North America. 2005;15(4):755-65, ix.

[139] Madeira MD, Pereira PA, Silva SM, Cadete-Leite A, Paula-Barbosa MM. Basal forebrain neurons modulate the synthesis and expression of neuropeptides in the rat suprachiasmatic nucleus.

Neuroscience. 2004;125(4):889-901.

[140] Erhardt C, Galani R, Jeltsch H, Cassel JC, Klosen P, Menet JS, et al. Modulation of photic resetting in rats by lesions of projections to the suprachiasmatic nuclei expressing p75 neurotrophin receptor. The European journal of neuroscience. 2004;19(7):1773-88.

[141] Craig LA, Hong NS, Kopp J, McDonald RJ. Cholinergic depletion of the medial septum followed by phase shifting does not impair memory or rest-activity rhythms measured under standard light/dark conditions in rats. Brain research bulletin. 2009;79(1):53-62.

[142] Gais S, Born J. Low acetylcholine during slow-wave sleep is critical for declarative memory consolidation. Proceedings of the National Academy of Sciences of the United States of America. 2004;101(7):2140-4. 
[143] Burns A, Rossor M, Hecker J, Gauthier S, Petit H, Möller HJ, et al. The Effects of Donepezil in Alzheimer's Disease - Results from a Multinational Trial. Dementia and geriatric cognitive disorders. 1999;10(3):237-44.

[144] Zhou J-N, Liu R-Y, van Heerikhuize J, Hofman MA, Swaab DF. Alterations in the circadian rhythm of salivary melatonin begin during middle-age. Journal of Pineal Research. 2003;34(1):11-6. [145] Liu RY, Zhou JN, van Heerikhuize J, Hofman MA, Swaab DF. Decreased melatonin levels in postmortem cerebrospinal fluid in relation to aging, Alzheimer's disease, and apolipoprotein Eepsilon4/4 genotype. The Journal of clinical endocrinology and metabolism. 1999;84(1):323-7.

[146] Wu YH, Zhou JN, Van Heerikhuize J, Jockers R, Swaab DF. Decreased MT1 melatonin receptor expression in the suprachiasmatic nucleus in aging and Alzheimer's disease. Neurobiol Aging. 2007;28(8):1239-47.

[147] Baskett JJ, Broad JB, Wood PC, Duncan JR, Pledger MJ, English J, et al. Does melatonin improve sleep in older people? A randomised crossover trial. Age and ageing. 2003;32(2):164-70.

[148] Hughes RJ, Sack RL, Lewy AJ. The role of melatonin and circadian phase in age-related sleepmaintenance insomnia: assessment in a clinical trial of melatonin replacement. Sleep. 1998;21(1):5268.

[149] Jean-Louis G, von Gizycki H, Zizi F. Melatonin effects on sleep, mood, and cognition in elderly with mild cognitive impairment. J Pineal Res. 1998;25(3):177-83.

[150] Zhdanova IV, Wurtman RJ, Regan MM, Taylor JA, Shi JP, Leclair OU. Melatonin treatment for age-related insomnia. The Journal of clinical endocrinology and metabolism. 2001;86(10):4727-30.

[151] Yesavage JA, Friedman L, Ancoli-Israel S, Bliwise D, Singer C, Vitiello MV, et al. Development of diagnostic criteria for defining sleep disturbance in Alzheimer's disease. Journal of geriatric psychiatry and neurology. 2003;16(3):131-9.

[152] Maywood ES, Mrosovsky N, Field MD, Hastings MH. Rapid down-regulation of mammalian Period genes during behavioral resetting of the circadian clock. Proceedings of the National Academy of Sciences of the United States of America. 1999;96(26):15211-6.

[153] Shochat T, Martin J, Marler M, Ancoli-Israel S. Illumination levels in nursing home patients: effects on sleep and activity rhythms. Journal of sleep research. 2000;9(4):373-9.

[154] Ancoli-Israel S, Gehrman P, Martin JL, Shochat T, Marler M, Corey-Bloom J, et al. Increased light exposure consolidates sleep and strengthens circadian rhythms in severe Alzheimer's disease patients. Behavioral sleep medicine. 2003;1(1):22-36.

[155] Yamadera H, Ito T, Suzuki H, Asayama K, Ito R, Endo S. Effects of bright light on cognitive and sleep-wake (circadian) rhythm disturbances in Alzheimer-type dementia. Psychiatry and clinical neurosciences. 2000;54(3):352-3.

* [156] Najjar RP, Zeitzer JM. Temporal integration of light flashes by the human circadian system. The Journal of clinical investigation. 2016;126(3):938-47.

[157] Riemersma-van der Lek RF, Swaab DF, Twisk J, Hol EM, Hoogendijk WJ, Van Someren EJ. Effect of bright light and melatonin on cognitive and noncognitive function in elderly residents of group care facilities: a randomized controlled trial. Jama. 2008;299(22):2642-55.

[158] Vieira E, Burris TP, Quesada I. Clock genes, pancreatic function, and diabetes. Trends in Molecular Medicine. 2014;20(12):685-93.

[159] Fuller PM, Gooley JJ, Saper CB. Neurobiology of the Sleep-Wake Cycle: Sleep Architecture, Circadian Regulation, and Regulatory Feedback. Journal of biological rhythms. 2006;21(6):482-93. 


\section{Figures}

\section{[Figure 1_Molecular Clock (300dpi)]}

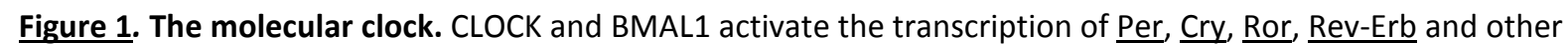
output genes controlled by the clock (CCG) via E-box elements. PER and CRY heterodimerize following phosphorylation in the cytosol and translocate to the nucleus where they inhibit CLOCK-BMAL1 transcriptional activation. In addition, REV-ERB (inhibition) and ROR (activation) also regulate Bmal1 gene expression by competing for binding to the RORE sequence in the Bmal1 promoter region. CLOCK, circadian locomotor output cycles kaput; BMAL1, brain and muscle Arnt-like protein-1. Original figure obtained from Vieira et al. 2014 [158].

[Figure2_SCN efferent $\&$ afferent pathways (300dpi)]

Figure 2. Afferent and efferent pathways of the SCN involved in the regulation of the sleep-wake cyle. This scheme illustrates how the SCN projects to its target regions and conveys the circadian rhythm to non-rhythmic effector cells of the sleep-wake cycle. The SCN receives information about the environment via two main pathways. The retinohypothalamic tract conveys information about external light levels, and the intergeniculate leaflet (IGL) and raphe nuclei (RN) send time cues that allow for non-photic entrainment. The SCN projects densely to the subparaventricular zone (SPZ), of which the ventral part (vSPZ) is involved in the regulation of activity patterns, the sleep-wake rhythm and feeding times, while the dorsal part (dSPZ) is responsible for body temperature rhythms. The SCN and VSPZ have many projections to the dorsomedial nucleus of the hypothalamus (DMN). The DMN is an important relay station for the regulation of the sleepwake cycle. From here, GABAergic fibers project to the ventrolateral preoptic nucleus (VLPO), the central center for sleep, and glutamatergic fibers project to the orexinergic lateral hypothalamic area (LHA), which is involved in waking. Other pathways that are important in the regulation of the sleep-wake cycle are the efferent projections to the PVN and further to the pineal gland. Melatonin is able to promote sleep, independently on the time of day. More importantly melatonin provides an important feedback mechanism for 
the SCN. Through the activation of melatonin receptors in the SCN, melatonin can have both phase shifting and sleep-promoting effects. Glu, Glutamate; PACAP, Pituitary adenylate cyclase-activating polypeptide; NPY, Neuropeptide Y; 5-HT, Serotonin; GABA, gamma-aminobutyric acid. Based on Fuller et al. (2006) [159]. 


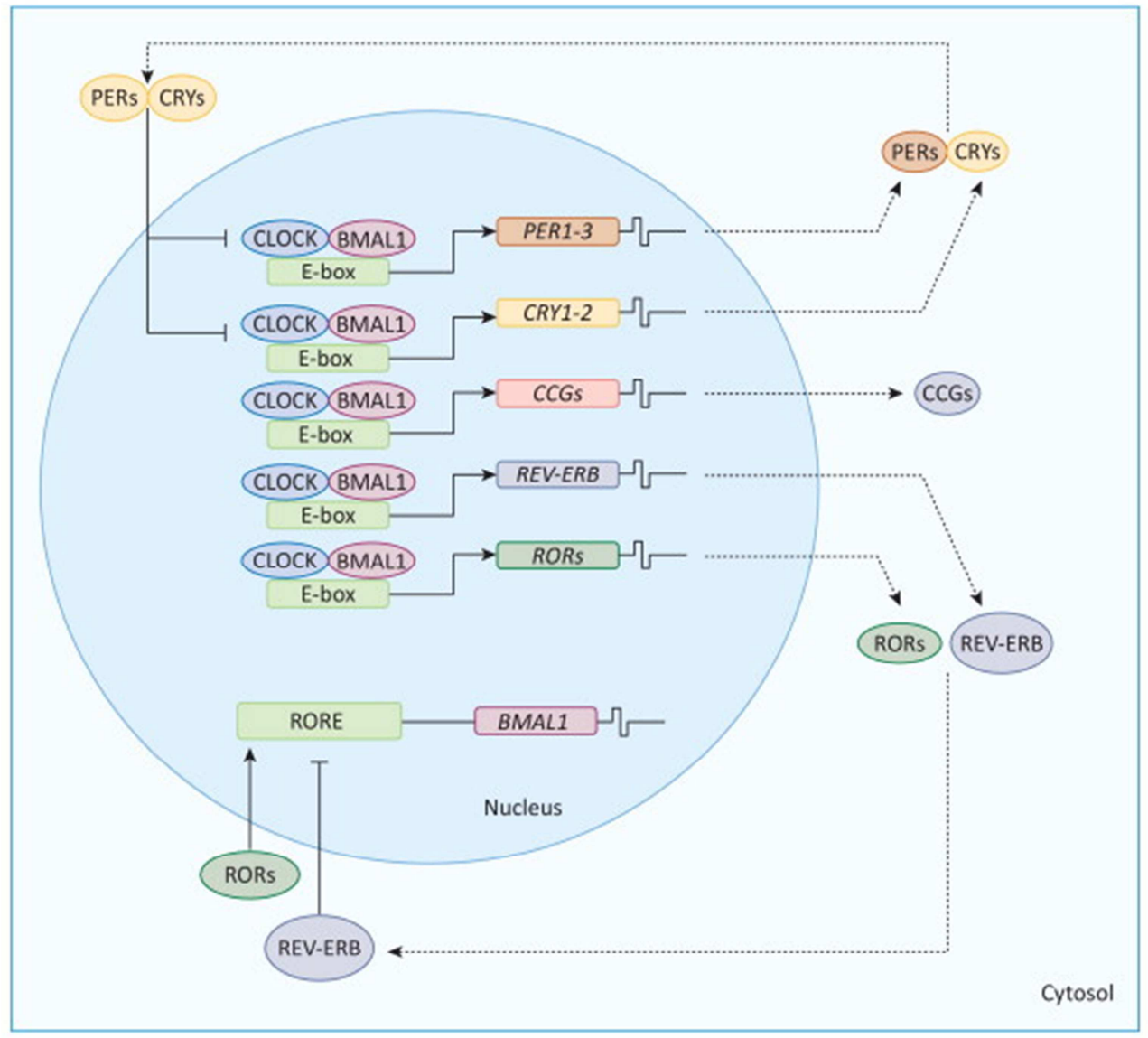




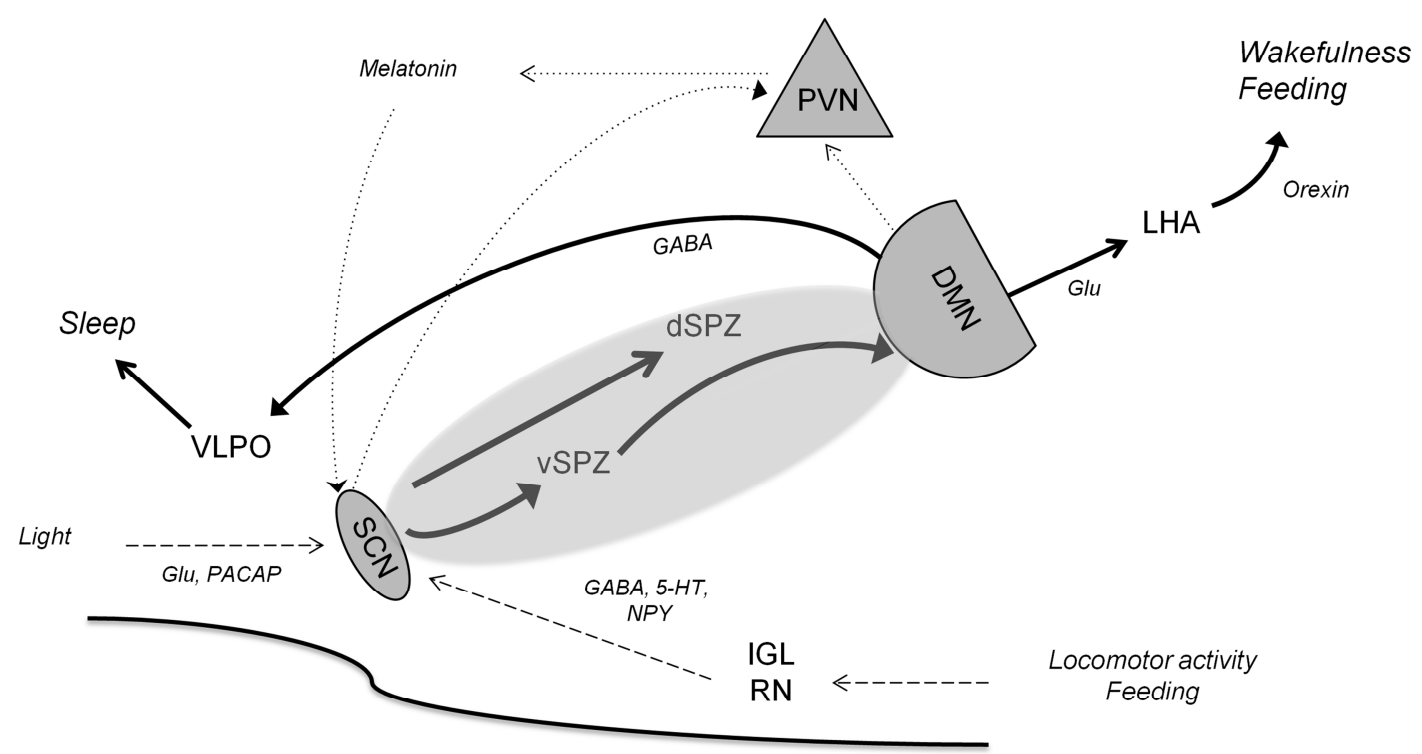

